\title{
Psicanálise no século XXI: um estudo sobre universidades do Rio de J aneiro e Buenos Aires
}

\section{Psychoanalysis in the $21^{\text {st }}$ century: a study about universities of Rio de J aneiro and Buenos Aires}

\section{Psicoanálisis en el siglo XXI : un estudio sobre universidades de Rio de Janeiro y Buenos Aires}

\author{
María Eugenia González* \\ Universidad Nacional de Salta - UNSA, Salta, Argentina
}

\begin{abstract}
RESUMO
Este artigo se propõe a analisar a situação da psicanálise nos cursos de psicologia das universidades do Rio de Janeiro, estabelecendo uma comparação com o caso de Buenos Aires. Para tal fim, utiliza um método de análise que implica construção documental, entrevistas e estudo teórico sobre a história e a atualidade da psicologia e da psicanálise nessas cidades. Entende-se que, além da chamada "crise" da psicanálise, ela mantém uma posição predominante nesses cursos. Espera-se que este trabalho contribua para uma discussão contextualizada dos cursos de psicologia em suas revisões curriculares.

Palavras chave: Psicanálise, Universidade, Psicologia, Argentina, Brasil.
\end{abstract}

\section{ABSTRACT}

We aim to analyse the situation of psychoanalysis in psychology undergraduate courses from universities of Rio de Janeiro, comparing these with the ones from Buenos Aires. For that purpose, we use a method of analysis that involves documental construction, interviews and theoretical study on the past history and the present reality of psychology and psychoanalysis in those cities. We understand that, besides the so-called "crisis" of psychoanalysis, this theoretical orientation maintains a predominant position in those courses. We expect that this work contributes to a contextualized discussion of psychology undergraduate courses and their curricular revisions.

Keywords: Psychoanalysis, University, Psychology, Argentina, Brazil.

\section{RESUMEN}

Se propone analizar la situación del psicoanálisis en las carreras de psicología de universidades de Rio de Janeiro, estableciendo una comparación con el caso de Buenos Aires. Para tal fin, se utiliza un método de análisis que implica construcción documental, entrevista y estudio teórico, sobre la historia y actualidad de la psicología y el psicoanálisis en esas ciudades. Se entiende que, más allá de la llamada "crisis" del psicoanálisis, éste mantiene una posición predominante en esos cursos. Se espera que este trabajo contribuya a una discusión contextualizada de las carreras de Psicología y sus revisiones curriculares.

Palabras clave: Psicoanálisis, Universidad, Psicología, Argentina, Brasil. 


\section{I ntrodução}

As ideias freudianas têm circulado por meio de um conjunto de representações culturais e instituições, se difundindo por toda a cultura de Ocidente e também em alguns países do Oriente. Particularmente, as cidades de Buenos Aires e do Rio de Janeiro têm sido consideradas, na atualidade, como capitais mundiais da psicanálise, comparáveis talvez somente com o caso de Paris (Plotkin, 2009).

No caso de Buenos Aires se destaca o predomínio histórico da disciplina psicanalítica no âmbito acadêmico, particularmente nos programas de graduação em psicologia, ao ponto de configurar o perfil do psicólogo e estabelecê-lo como um dado natural pela sociedade (Dagfal, 2009).

Também no Rio de Janeiro, desde meados da década de 1970 a psicanálise teve influência na formação dos psicólogos. Porém, foi maior nos grupos de formação extra universitários, onde sua presença era predominante (Figueiredo, 1984). Além disso, nessa cidade, atualmente, no âmbito universitário aparentemente a maioria dos estudantes que frequenta os cursos de psicologia aspira ter uma formação teórica voltada para a clínica dentro do modelo tradicional do atendimento individual (Dimenstein, 2000).

Neste sentido, vários autores têm afirmado que a área clínica tem tido muita relevância na formação em Psicologia no Brasil. Esta área tem sido escolhida, majoritariamente, como ênfase da formação em Psicologia, pelos estudantes de diferentes cursos desse país (Fernandes, 2016). Além disso, tem sido qualificada como "hegemônica" não somente no ensino de conteúdos em Psicologia (Seixas, 2014), senão também nos campos de aplicação profissional dos psicólogos brasileiros (Bastos \& Gondim, 2010). ${ }^{1}$

Por conseguinte, a naturalização a respeito da psicanálise existente nas duas cidades precisa ser situada social e historicamente. A ideia do predomínio clínico psicanalítico determina e configura as práticas dos profissionais em psicologia - assim é preciso historicizá-la e trabalhá-la em suas características específicas. É necessário considerar que a forte relação entre psicologia e psicanálise nos dois países supõe um processo histórico e social com traços específicos que aparentemente hoje estão mudando aceleradamente.

$\mathrm{Na}$ atualidade, uma chamada "crise" da psicanálise (Cerqueira, 1982; Coelho Junior, 1999; Garza-Guerrero,2002; Campuzano, 2005; Lezé, 2010; Roudinesco \& Plon, 1998; Roudinesco, 2003, 2012; Hornstein, 2013, Porge et al., 2015) tem lugar nos debates profissionais do campo "psi". Entre outras características, ela implica que não se pode ignorar a crescente presença da orientação cognitivo-comportamental, das neurociências, assim como a proliferação das terapias breves e também dos discursos sobre terapias complementárias ou das que provêm do movimento "New Age". 
Ao mesmo tempo, também se modifica o cenário dos novos atores institucionais do mercado da saúde (como, por exemplo, a medicina dos planos de saúde privados que exige tratamentos curtos e estandardizáveis). Isto implica novos desafios, que situam os psicanalistas numa posição de ter que dar conta da eficácia da sua própria prática em termos compreensíveis para os pacientes e aceitáveis para outros atores institucionais com poder de decisão.

Por outro lado, no plano institucional, as universidades dos dois países e consequentemente os cursos de graduação em psicologia nelas inseridos - têm se fortalecido desde finais do século XX e nos inícios do século XXI. Particularmente no Brasil se produziu um fenómeno de expansão do sistema de educação superior durante a década do 2000 e nos inícios da década de 2010, por meio de políticas públicas democratizantes (Dantas, 2017). Esse processo de expansão também está associado à liberalização e ao crescimento do setor privado (Dias Sobrinho \& Brito, 2008) e se produziu principalmente nas regiões Norte, Nordeste e Centro-Oeste (Yamamoto, Falcão, \& Seixas, 2011). No caso de Argentina, atualmente existem 41 cursos de psicologia funcionando - dos quais 31 são privados. Nesse país, estes cursos têm produzido mais de 101.000 graduados no total (Alonso \& Klinar, 2016). Essa massividade dos estudos em psicologia na Argentina já está ultrapassando as chamadas "profissões tradicionais". ${ }^{2}$

Desta forma, considerando por um lado a chamada "crise" da psicanálise no mundo mas, por outro lado, levando em conta a força institucional dos cursos de psicologia adquirida no início do século XXI nos dois países, analisa-se aqui se a psicanálise nas suas distintas orientações dentro do âmbito acadêmico mantém o lugar predominante, historicamente construído nas disputas pela hegemonia nos currículos em psicologia, na Argentina e também no Brasil - embora neste último não seja tão forte como na Argentina. Então, este artigo analisa a situação da psicanálise nos cursos de graduação em psicologia das principais universidades do Rio de Janeiro, estabelecendo uma comparação com o caso de Buenos Aires.

É importante apontar que este trabalho está apoiado, em primeiro lugar, de uma perspectiva histórico-crítica e de história cruzada. Para a nossa análise histórica, a perspectiva crítica permite realizar um afastamento das reconstruções feitas desde o interior do movimento psicanalítico (Danziger, 1984; Vezzetti, 2000). Por conseguinte, aqui é utilizada uma visão crítica em relação às fontes e autoridades históricas tradicionais, às perguntas do próprio investigador e para a disciplina (Danziger, 1984). Na sociologia, este aspecto remete ao que Pierre Bourdieu denominou de "reflexividade" (Bordieu, 2001).

Dado que esta pesquisa aborda problemáticas de dois países diferentes, também a perspectiva de história cruzada (Werner \& Zimmermann, 2006) será de utilidade já que, diferentemente da história comparada, este olhar inclui os pressupostos do pesquisador, e não o entende como 
alguém externo ou neutro. Desta forma, se defende a ideiade que a escrita deste texto não pode ser neutra, já que forma parte das lutas pela hegemonia nos currículos universitários e, neste caso, especificamente na comunidade psicológica (Lopes, 2013).

Por outro lado, dado que aqui se abordam os currículos em psicologia das universidades do Rio de Janeiro e de Buenos Aires, é preciso esclarecer o que se entende pelo termo "currículo". Aqui este não é trabalhado desde uma visão tecnicista como um instrumento pelo qual se programam definições educativas. Este conceito é aqui compreendido como uma prática de poder (Macedo, 2006). Adota-se também para nossa pesquisa uma perspectiva de política de currículo como uma política cultural, na qual alguns grupos sociais particulares são capazes de se articular entre si, na defesa de suas diferentes demandas curriculares (Lopes, Evangelista Dias, \& Gomes de Abreu, 2011).

\section{Metodologia}

Nosso trabalho abrangeu distintas etapas, que consistiram em pesquisa da literatura, na análise do nível formal do currículo (planos de estudo e programas das disciplinas selecionadas) e na análise das práticas curriculares, que implicaram na realização de entrevistas e a sistematização dessa informação.

O recorte temporal de nossa investigação se inicia com os primeiros programas de pós-graduação em psicanálise, nos finais dos anos 1980 e princípios dos anos 1990 (Universidade Federal do Rio de Janeiro: 1988, Universidade do Estado do Rio de Janeiro: 1998) até a atualidade. Esse momento inicial representa a institucionalização da psicanálise nas principais universidades do Rio de Janeiro, e é quando a sua presença nestas universidades "se tornou uma realidade" (Coutinho, Mattos, Monteiro, Virgens, \& Almeida Filho, 2013, p. 111).

O método de análise implica pesquisa documental, entrevista e estudo sobre a história e a situação atual da psicologia e da psicanálise no Brasil. Por pesquisa documental se entende a busca e seleção de documentos considerados relevantes para a pesquisa. No caso, são os planos de ensino, e os programas de disciplinas introdutórias e de períodos finais de quatro cursos de graduação em psicologia de universidades do Rio de Janeiro e de universidades de Buenos Aires. Esta escolha se baseou no nível de importância dessas universidades - em relação à quantidade de alunos formados que elas têm - e foram selecionadas tanto universidades de gestão pública quanto de gestão particular (privada), entendendo que se visualizam diferenças entre elas na análise deste fenômeno. Realiza-se uma análise quantitativa das disciplinas psicanalíticas nos planos de ensino, e uma análise bibliométrica das referências bibliográficas obrigatórias de dois grupos de disciplinas 
diferentes. Aqui são observados os autores principais e suas orientações teóricas.

As entrevistas foram semiestruturadas e realizadas primeiramente com os quatro coordenadores dos cursos de graduação em psicologia escolhidos no Rio de Janeiro. Depois, também foram entrevistados dois estudantes e dois professores de cada uma das quatro universidades selecionadas do Rio de Janeiro. Os estudantes foram selecionados sob uma amostragem não probabilística, por conveniência. No que se refere aos professores, entrevistou-se um professor de uma disciplina introdutória e um professor de uma disciplina do ciclo profissional de cada curso de psicologia. Na cidade do Rio de Janeiro foram realizadas vinte entrevistas.

O conteúdo dessas entrevistas versou sobre aspectos como: professores importantes na formação do entrevistado; autores relevantes nas matérias ensinadas ou cursadas; visão geral sobre a formação nesse curso de graduação em psicologia em particular; opinião sobre as relações entre psicologia e psicanálise nos planos teórico e institucional; opinião sobre o enfoque predileto dos estudantes e, no caso dos professores, auto representação como psicanalista; dificuldades para conciliar esta função com a docência universitária. Pretendeu-se, com isto, mostrar formas da circulação, difusão e reprodução do discurso psicanalítico e seus possíveis modos de legitimação.

O trabalho nas universidades argentinas foi realizado com os mesmos critérios que o trabalho nas universidades do Rio de Janeiro. As únicas diferenças decorreram de que, em primeiro lugar, na Argentina nem todos os cursos escolhidos contam com a função de "coordenação". Assim, não foi possível fazer esse tipo de levantamento de dados nas universidades argentinas. Por isto, ali foram consultados apenas dezesseis agentes (quatro de cada universidade). Em segundo lugar, na Argentina utilizou-se a modalidade de questionário aberto, respondido de forma escrita e não de forma oral, como na modalidade de entrevista.

Cabe esclarecer que, com a realização destas entrevistas, não se pretende realizar uma amostragem representativa do sub-campo "psi" acadêmico (carioca ou portenho). Aqui selecionam-se agentes que podem refletir trajetórias diferentes dentro do percurso curricular e posições diversas dentro do campo. Finalmente, foram realizadas comparações destes resultados. Assim, espera-se contribuir para uma discussão contextualizada nos cursos de psicologia em suas revisões curriculares.

\section{Antecedentes históricos}

Em relação à expansão psicanalítica nos dois países, no caso do Brasil a psicanálise já era difundida na cultura popular e na vida cotidiana nas primeiras décadas do século $\mathrm{XX}$, durante a etapa prévia à 
institucionalização da psicanálise. Antes de chegaram os enviados da IPA para formar aos primeiros psicanalistas brasileiros, já estavam disseminadas as ideias do médico vienense (Russo, 2002a; 2002b). Também agentes do campo psiquiátrico as incorporavam tanto nas suas práticas quanto em textos, muitas vezes vinculando-as a pressupostos organicistas e às teorias da degenerescência.

Nas décadas de 1960 e 1970 ocorreu o boom psicanalítico que significou um momento chave para a implantação de uma cultura psi brasileira (Figueiredo, 1984, 2012; Figueira, 1985; Dimenstein, 2000; Pereira \& Pereira Neto, 2003; Russo, 2012). Já ao final da década de 1980, a psicanálise conseguiu autonomia e presença dentro dos cursos de psicologia das universidades brasileiras (Birman, 2000). Posteriormente, nas décadas seguintes, segundo Coimbra (1999), os estudantes de psicologia tinham os psicanalistas - do mesmo modo que na Argentina como modelos de referência e almejavam trabalhar num consultório privado.

No caso argentino, as primeiras leituras da psicanálise realizadas no país ocorreram no fim do século XIX e início do século XX nos círculos psiquiátricos, sendo que desde fins da década de 1920 a psicanálise ultrapassou o plano médico, e começou a ser difundida no âmbito cultural e social (Vezzetti, 1996a, 1996b). Sua influência na cultura popular foi forte a partir de meados do século XX (Plotkin, 2003) e, com a criação dos programas de graduação em psicologia, a psicanálise logrou chegar aos cursos universitários de forma ampla (Dagfal, 2009). Neste país, o psicólogo tem sido associado às práticas psicanalíticas em suas distintas orientações. No final da década de 1960, a psicanálise já havia sido adotada por uma grande quantidade de psicólogos, não somente como marco teórico preferido, mas também como referência identitária (Litvinoff \& Gomel, 1975; Klappenbach, 2000). Nas décadas seguintes, a figura do "psicólogo psicanalista" foi se consolidando no campo profissional, no âmbito acadêmico e na vida cultural. Também no Brasil, durante as décadas de 1960 e 1970, os psicólogos psicanalíticos foram se fortalecendo, entretanto sem contar com a possibilidade de formação nas sociedades oficiais (Figueiredo, 1984).

Neste sentido, como já mencionado, um fator comum nos dois países é a forte vinculação entre a psicanálise e a psicologia. E é importante lembrar que a chamada psicologia psicanalítica no Brasil foi influenciada pelos argentinos que chegaram ao país por motivos políticos; embora eles já viessem desde os anos 1960, trazendo suas novas técnicas, é nos anos 1970 que esta vinculação se fortalece (Figueiredo, 2012). Devido à ruptura política ocasionada pela ditadura argentina, a formação psicanalítica oferecida pelos argentinos a um segmento de psicólogos brasileiros neste período teve ênfase na politização e no compromisso social, trazendo influências teóricas marxistas. Esta presença propiciou assim a forte influência da perspectiva da análise institucional nos cursos de psicologia. ${ }^{3}$ Com o decorrer dos anos, essa perspectiva perdeu força 
no movimento psicanalítico no Brasil devido a que, por um lado, os institucionalistas ficaram mais conectados com a psicologia social, e por outro lado à marca lacaniana, que se expandiu e se mantém até os dias de hoje.

Na Argentina o lacanismo também possui forte presença, sendo que sua expansão data do retorno à democracia. No período de 1976 a 1983, a intervenção da ditadura militar modificou os currículos e fechou cursos de graduação em psicologia (Carpintero \& Vainer, 2005). Mais tarde, as ideias lacanianas se disseminaram nas instituições universitárias e na formação oferecida pelas associações psicanalíticas, da mesma forma que no Brasil. Hoje, os dois países são polos de desenvolvimento da psicanálise fundamentalmente lacaniana ao nível internacional.

\section{Análise de documentos e das práticas curriculares}

Em primeiro lugar, nos documentos revisados é possível observar que todos os quatro cursos de graduação em psicologia das universidades do Rio de Janeiro têm de uma a três disciplinas obrigatórias com o termo "Psicanálise" ou seus derivados no título ("Técnica psicanalítica", "Teoria psicanalítica", "Psicologia e Bases do Pensamento Psicanalítico", "Psicanálise" "Terapia Psicanalítica"). Entanto, segundo alguns dos nossos consultados, outras disciplinas também "tem esse viés psicanalítico por trás" (Christian). ${ }^{4}$ Em relação a um caso de um curso especifico do Rio de Janeiro, um professor afirmou:

"Mesmo aquelas (disciplinas) que não deveriam ser, o que os alunos trazem, inclusive como queixa, é que elas têm sempre um olhar psicanalítico, mesmo nas que não são. Porque o professor é psicanalista, então ele acaba fazendo uma leitura do campo, muito psicanalítica" (Baltasar).

Neste sentido, os entrevistados brasileiros em geral reconheceram uma grande presença da psicanálise nos currículos de psicologia, além das ênfases particulares de cada uma das universidades.

No caso de Buenos Aires ocorre um fenômeno similar: dos cursos escolhidos, três deles têm de uma a quatro disciplinas obrigatórias com o termo "psicanálise" no título ("Psicoanálisis Freud", "Teoría psicoanalítica", "Teoria Del psicoanálisis", "Práctica psicoanalítica", "Desarrollos del psicoanálisis"). Porém, o único curso que não conta com disciplinas com clara denominação voltada à psicanálise mostra, segundo os resultados da análise bibliográfica realizada nos programas selecionados, Freud como um dos autores mais presentes. Além disto, também os alunos argentinos ressaltaram o fato de ter uma formação preponderantemente psicanalítica. Um deles sublinhou isto da forma 
seguinte: "Es casi excluyente la formación en psicoanálisis en esta universidad, y dentro de este, en el freudiano y/o lacaniano." (Arturo).

Por outro lado, o resultado da resposta à pergunta sobre o autor mais estudado na formação universitária apresenta um dado relevante: a totalidade dos alunos, tanto argentinos quanto brasileiros, de universidades públicas e particulares, mencionaram em primeiro lugar a Sigmund Freud como o autor mais referenciado nas disciplinas cursadas. Avançando então para a análise bibliométrica realizada neste caso, trabalhou-se com as referências bibliográficas obrigatórias dos programas das primeiras disciplinas introdutórias à psicologia dos cursos escolhidos. ${ }^{5} \mathrm{O}$ mesmo procedimento foi realizado com as disciplinas profissionalizantes, onde o critério padrão foi escolher a primeira disciplina de Psicopatologia presente nos planos de ensino. Assim, foi possível observar o lugar da psicanálise em relação a outros olhares teóricos, por meio da análise dos autores mais referenciados em cada uma das disciplinas.

Quanto aos programas das disciplinas escolhidas para nossa análise em Buenos Aires, no caso das disciplinas introdutórias ("Introducción a La psicología", "Psicología general", "Psicología I" etc.) a variedade de autores indicados nos programas resultou ser bem heterogênea. Aí predominaram autores que podem ser classificados como socio-culturais, cognitivos, interdisciplinares e até textos de índole geral como, por exemplo, manuais. No caso das disciplinas profissionalizantes ("Psicopatología" "Psicopatología I" "Psicopatología General y Especial" "Psicopatología de La Adultez"), conforme esperado, o autor predominante foi Sigmund Freud nos quatro cursos - referenciado com percentagens que variaram desde $33 \%$ até $97 \%$. É preciso mencionar que nos cursos de psicologia de gestão pública, o autor referenciado em segundo lugar foi Jacques Lacan.

Considerando as emendas das disciplinas escolhidas nos cursos do Rio de Janeiro, é possível observar um fenômeno similar ao caso de Buenos Aires: as disciplinas introdutórias apresentam uma índole mais diversificada em relação ao(s) autor(es) indicados, e as disciplinas de Psicopatologia elegem Freud como referência principal. 6

Já em relação aos motivos alegados para a presença do discurso psicanalítico nos currículos, nossos entrevistados brasileiros referiram-se em alguns casos somente à "tradição" psicanalítica desses cursos em particular, devido à presença de professores que começaram a trabalhar aí e tinham essa orientação teórica. Desta forma, entende-se que uma tradição curricular condiciona as formas de interpretação dos agentes que atualmente disputam as significações curriculares em psicologia. A história constitui também um discurso com o qual alguns grupos operam na atualidade e, portanto, sempre é reconstruída em relação ao tempo presente (Lopes, Evangelista Dias, \& Gomes de Abreu, 2011).

Argumentou-se, nesta direção, a existência previa de grupos de psicanalistas que se organizaram para manifestar suas demandas de 
crescimento dentro da instituição, por exemplo, por meio da criação dos programas de pós-graduação em psicanálise nos começos dos anos 1990 (Christian). Também no caso de uma universidade particular do Rio de Janeiro, esta herança foi vinculada de maneira mais ampla à importância geral da psicologia clínica (Bruno). Em relação a este tópico, alguns argentinos destacaram também o fundamento dessa "tradição":

"(Existe) una necesidad temprana de diálogo que se le impone al estudiante de psicología argentino entre su ser como psicólogo y su ser como psicoanalista; es parte de nuestra herencia, de nuestra tradición, me parece coherente que hagamos este diálogo." (Andrés).

Por outro lado, os argentinos ressaltaram a qualidade de ensino dos professores, sobretudo desses que ensinam psicanálise em alguns cursos de gestão pública:

"El psicoanálisis en la facultad es potente (...) por la calidad de los profesores, en relación a su formación, los problemas que se están abordando, y las lecturas que se están realizando. Creo que hay una presencia del psicoanálisis en la Facultad que es fuerte, pero más que nada en términos cualitativos, por tradición e identidad." (Adrián).

De qualquer forma, estes motivos também se encontram vinculados à importância dos contextos institucionais de cada um dos cursos que propiciaram esta expansão. As instituições universitárias constituem modos de interpretar e conceber o currículo. Nelas se elaboram os diagnósticos, as problemáticas e as soluções curriculares, ao mesmo tempo que elas criam também os contextos disciplinares (Bowman, 2007). Assim, por exemplo, entrevistados brasileiros falaram sobre como essas condições institucionais de uma universidade pública de Rio de Janeiro alimentam a expansão da psicanálise:

"O pessoal da psicanálise é muito forte, aparentemente, para nós alunos (...) Claro que cada um deve ter sua própria visão, mas eles se juntam para defender à psicanálise no Instituto, entendeu? E acaba, devido talvez a essa união, que eles têm um espaço grande na grade do curso." (Bryan).

"...(H)istoricamente as outras abordagens não fizeram um movimento organizado (...) como proposta de marcar um espaço dentro da graduação. E eu acho que o corpo de professores psicanalistas tomou isso como meta, e conseguiram um espaço que hoje, dentro da clínica, eu acho que é um espaço significativo (...) eles têm interesse de disseminar, legitimamente, a 
abordagem deles (...) são muitos mesmo e então, o curso, acaba tendo um viés muito mais psicanalítico..." (Baltasar).

Também em outra universidade pública brasileira, um entrevistado falou sobre a necessidade de haver vagas para professores de outras linhas:

"Se você gosta de determinada linha, às vezes, você fica restrito a um professor; sabe, como Gestalt, ele é o único humanista existencial. Na psicanálise, você pode se ligar a outras pessoas. Então acho que esse é um pouco meu mal-estar, sabe. De não ter tanto espaço como a psicanálise tem." (Benicio).

Da mesma forma, alguns estudantes argentinos provenientes de cursos de psicologia de universidades públicas também alegaram que a forte presença da psicanálise nessas instituições é decorrente das linhas curriculares dos planos de ensino, os quais, segundo sua opinião, deveriam ser modificados:

"Uno se egresa siendo un licenciado, solamente un teórico del psicoanálisis. La formación (...) debería ofrecer múltiples materias obligatorias, y no optativas, sobre terapia cognitivo conductual, terapia sistémica..." (Arturo)

"No es una carrera que incluya a las principales corrientes actuales en psicología. Un egresado puede no haber leído nunca un texto de terapia conductista, cognitiva, sistémica, Gestalt, solo por nombrar algunas de ellas. En este sentido cambiaría muchas cosas del plan de estudio." (Adolfo).

Por outro lado, quando se perguntou aos professores argentinos sobre a atualidade da difusão da psicanálise, e de sua escolha pelos estudantes de psicologia, alguns argumentaram que esse olhar hoje estaria declinando: "Hasta hace algunos años había una preferencia por La orientación psicoanalítica em la clínica. Hoy creo que ya no es tan así...". (Adán)

Alegou-se como causa, em Buenos Aires, a falta de eficácia para as problemáticas atuais e o importante avanço da psicologia cognitiva:

"En la actualidad (el psicoanálisis) no da respuesta a la mayoría de las demandas en salud mental. Hay muy pocos psicoanalistas que hacen investigaciones serias y basadas en la evidencia. De esto se diferencia claramente de otros modelos teóricos, más ligados al conocimiento científico." (Adolfo)

"El cognitivismo se plantea como una técnica eficiente y de resultados rápidos, y parece tener respuesta para todo. A primera 
vista parece una propuesta terapéutica más acorde a nuestra época donde impera la eficiencia rápida. El psicoanálisis exige mayor esfuerzo y la mayoría de los alumnos no parece estar bien dispuesto para los esfuerzos." (Agustín)

No caso do Rio de Janeiro, a justificativa sobre este fenômeno refere-se à importância dos novos professores de outras orientações teóricas que têm ingressado aos cursos de psicologia nos últimos anos e que ensinam e promovem estas ideias. Neste sentido, a diferença do sistema universitário brasileiro outorga uma mobilidade maior para a mudança dos professores: "...aqui não são cátedras, em principio é o professor, ele continua dando a disciplina, mas não é um cargo vitalício". (Benedito).

Assim, quanto ao avanço de outros olhares teóricos nos cursos de graduação em psicologia, outros entrevistados brasileiros afirmaram:

"Tem acontecido que muitos dos psicanalistas estão se aposentando e está emergindo um novo grupo ligado a neuropsicologia, então, está mudando um pouquinho o perfil. (...) Desde 2000 em diante, foram crescendo também as outras clínicas." (Bernardo)

"Quando eu cheguei existia uma predominância claríssima pela psicanálise. (...). Entraram vários professores que trabalham com outras coisas depois, hoje eu acho que são muito diversificados. Acho que ainda tem uma predominância psicanalítica, mas ela não é mais tão acentuada quanto era. Acho que perdeu força." (Bonifacio)

Assim, têm sido importantes nas instituições cariocas as opiniões dos alunos e particularmente as demandas dos estudantes organizados em centros acadêmicos. Deste modo um entrevistado expressou, no caso duma universidade particular brasileira, "(Q)ue (os estudantes) estavam querendo não essa direção tão psicanalítica, tão presente." (Carlos). Na mesma linha, um entrevistado de outra universidade expressou: "A gente tem tido muita reclamação dos alunos porque eles acham que tem muita psicanálise agora, e pouco das outras ênfases." (Christian). Em um destes casos se mencionou a ação institucional de organizar concurso público de professores em áreas não psicanalíticas (Bruno).

Porém, no caso do Rio de Janeiro outros entrevistados também levaram em conta um forte acompanhamento dos alunos em relação à difusão da psicanálise. A causa disto aparentemente tem a ver com motivos internos à disciplina psicanalítica, como por exemplo, a "transmissão" da psicanálise: "A forma de transmissão da psicanálise, faz toda a diferença." (Casimiro). A diferença entre transmissão e formação reside em que a transmissão do conhecimento psicanalítico não pode ser realizada da mesma forma que a de outros tipos de saber. Entanto, essa 
diferença tem sido conceituada trasladando a discussão à orientação lacaniana. Tem-se argumentado que a diferença nos termos utilizados se expressa também na "necessidade que os lacanianos têm de fazer do seu texto uma tomada de posição" (Russo, 1993, p. 90-91).

Também é importante destacar que os nossos consultados expuseram maiores e menores níveis do conflito quanto à aceitação e resistência ao discurso psicanalítico por parte dos demais professores. Por um lado, argumentou-se que essa diferença pode ser de índole epistemológica e, neste sentido, as dificuldades vão existir sempre (Christian). Afirmou-se também que professores de diferentes orientações teóricas realizam em conjunto, com mais facilidade, trabalhos de tipo administrativo e institucional. A impossibilidade se produz quando eles devem fazer trabalhos de pesquisa (Christian). Essa falta de diálogo foi denunciada da seguinte forma:

"Eu acho que é um pouco compartimentado demais; não tem um espaço de diálogo entre os departamentos, entre os próprios professores. Por exemplo, eu não tenho a menor ideia, ou sei pouco dos colegas próximos ao meu trabalho, e sei nada dos colegas mais distantes." (Benedito).

"Talvez os programas não briguem entre si, as pessoas não brigam entre si porque elas não conversam, são muito isoladas. Cada um no seu eixo, cada um trabalhando com aquilo que trabalha e isso não gera conflitos, mas também não gera nenhum tipo de aproximação." (Bonifacio).

"E quase como se fosse uma barreira mesmo entre os professores. Tem os psicanalistas, que se leem entre eles. E tem os psicoterapeutas que também tem suas linhas. Não há diálogo. $O$ que eu escuto muito (...) é que há essa questão de que os psicoterapeutas não entendem a psicanálise como uma terapia. Ela é outra coisa (...) Não se cruzam". (Benjamim)

Tais diferenças epistemológicas foram mencionadas também nos depoimentos de argentinos, não somente alegando as dificuldades que supõe a convivência dos diferentes olhares psicológicos, mas declarando a importância de distinguir, especificamente, o status epistemológico da psicanálise(Axel). Assim, alguns argentinos defenderam a ideia de que a psicanálise se apresenta como superadora no campo da psicologia (Andrés; Adrián).

Chamou a atenção a forma como este debate sobre as visões teóricas foi expressa por alunos das duas cidades: em termos de "times de futebol".

"Eu acho que é como se fosse um time de futebol, os psicanalistas e os outros. No outro dia fui assistir a uma palestra, era uma 
mulher da TCC (Teoria Cognitiva Comportamental) e ela começou a palestra perguntando: 'Aqui há psicanalistas? Ah, somos amiguinhos, hein.' Então, há uma rixa muito grande e coisa de time de futebol. Ou você é isso ou você é aquilo e não há pontos meios." (Batista).

"...(É) como o futebol. Às vezes parece muito com isso, eu sou da Psicanálise, então não tolero nada do outro, é muito assim. 0 então, eu escolhi a Gestalt e não acredito nada do que você está me falando dos outros olhares. Tem uma disputa de saberes e, principalmente no campo da instituição, eu percebo isso na instituição." (Breno).

"Dentro de la corriente psicoanalítica hay mucho fanatismo. Como si fuese un equipo de futbol, si sos de acá no podés ser de allá. (...) En mi formación académica viví esto viendo el lugar en el que se paraban ciertos profesores para con el marco teórico elegido por ellos. Pocos casos encontré que haya profesores que aceptaran que todos los marcos teóricos alimentan a un profesional en su ejercicio diario." (Alfredo)

Dadas estas hostilidades, alguns cariocas e portenhos propuseram a necessidade de diálogo entre as distintas perspectivas, fundamentando que os cursos universitários de psicologia, por oposição às instituições psicanalíticas, podem ser um lugar de construção de novos desenvolvimentos (Benedito). Nas palavras de um entrevistado argentino: "La academia es un lugar donde el psicoanálisis puede desarrollarse con intercambios fructíferos" (Alfonso). Esta posição se afasta de outras que vislumbram uma psicologização da psicanálise e a consideram uma ameaça à circulação das ideias freudianas e um fator que intervém na crise da disciplina (Porge et al., 2010).

Também se mencionou a importância da possibilidade de diálogo entre os professores para oferecer aos estudantes uma pluralidade de olhares: "É preciso mostrar para os alunos, que um fenômeno, ele pode ser visto, estudado, a partir de diferentes abordagens, que elas não são contrastantes, elas são complementares" (Carlos).

Por causa disto, alguns entrevistados avaliam como positiva a formação oferecida por cada uma das universidades em estudo, já que para alguns professores brasileiros é valorizada, por exemplo, a formação "sem ênfase especifica" (Carlos), aspecto que possibilita garantir a pluralidade de perspectivas. Por outro lado, também é avaliada como positiva e é defendida a existência de um corpo de professores doutores, de qualidade educativa, membros ao mesmo tempo dos cursos de graduação e dos programas de pós-graduação (Christian), bem como o efetivo e rápido ingresso no mercado profissional dos formados (Casimiro). Tendo em vista que este último caso corresponde a uma 
universidade particular, é possível estabelecer uma relação entre essa característica e a vinculação mais direta com o mercado de trabalho.

Por sua parte, se alguns argentinos defendem que os cursos são amplos, gerais e multiteóricos, ${ }^{7}$ às vezes se referem a este fenômeno ora com uma conotação positiva, ora com uma negativa. Assim, por um lado, defendendo a formação dum dos cursos analisados, um professor afirmou: "(La carrera) es lo suficientemente amplia como para brindarle al alumno un panorama general respecto de lãs principales corrientes psicológicas, así como también de La actividad profesional em los diferentes ámbitos." (axel). De forma inversa, outros entrevistados se referiram à superficialidade desse tipo de formação geral e ampla em psicologia: "Muchas veces El contenido es tan superficial que se hace difícil tener una base fuerte. Quizás vendrían bien algunas materias anuales, bases más profundas en distintas teorías y paradigmas." (Antonio); "...(L)a formación es bastante heterogénea, pero esa amplitud lleva al riesgo de no profundizar el estudio de ninguna corriente en particular." (Agustín).

\section{Considerações finais}

Neste trabalho foi realizada uma aproximação ao fenômeno da expansão da psicanálise nos cursos de psicologia de Buenos Aires e do Rio de Janeiro. Para tal fim se apresentaram, em primeiro lugar, as bases teóricas e históricas para a análise desta situação. Posteriormente, foi realizada uma análise curricular através da abordagem de textos documentos e entrevistas - dos diferentes cursos selecionados.

Em conclusão, se defende a necessidade de incentivar o debate sobre a vinculação da psicanálise com a universidade, desde um olhar que analise o que efetivamente está acontecendo nas salas universitárias, em vez de propor postulados normativos sobre o que deveria ser feito ou não. Assim, se mostrou brevemente a forma como as ideias freudianas ingressaram nesses espaços universitários, como também se observou a influência dos psicanalistas argentinos no Brasil nesse processo histórico. Além de algumas dificuldades em relação à documentação dos cursos da cidade do Rio de Janeiro, como a curta extensão das emendas e as dificuldades para conseguir os programas das disciplinas, se observaram algumas similaridades em relação à presença de disciplinas psicanalíticas nos planos de ensino nas cidades de Buenos Aires e do Rio de Janeiro. Observou-se também a predominância do autor "Freud" nos programas das disciplinas escolhidas e a unanimidade de opiniões dos alunos das duas cidades, que alegaram unanimemente que Freud foi o autor mais estudado por eles.

Por outro lado, a influência da tradição psicanalítica foi referenciada pelos entrevistados de Buenos Aires e do Rio de Janeiro. Mostrou-se como alguns aspectos institucionais contribuem para modificar práticas 
curriculares e consequentemente se constroem discursos que operam atualmente nas aulas de psicologia, levando em conta essa "tradição" psicanalítica.

No caso do Rio de Janeiro, destacou-se a grande quantidade de professores psicanalistas nos cursos selecionados como um fator que determina a maior circulação do discurso psicanalítico. No caso de Buenos Aires, principalmente, aludiu-se ao currículo formal - os planos de ensino - como a causa principal do predomínio do discurso psicanalítico nos cursos de graduação em psicologia.

Porém, nas duas cidades houve manifestações de que a influência da psicanálise estaria declinando atualmente nos cursos de psicologia. No caso do Rio de Janeiro, foi alegado o ingresso de novos professores com outros olhares teóricos. Aí, contrariamente a Buenos Aires, o sistema de concursos de ensino superior é mais dinâmico, propiciando mais possibilidades de diversificação. Por outro lado, em Buenos Aires se defendeu a ideia de que a perda de influência psicanalítica é causada pela falta de eficácia da psicanálise em geral, em oposição à rápida resposta outorgada pelas terapias cognitivo-comportamentais.

Os coordenadores dos cursos e os professores cariocas reconheceram a importância da luta estudantil como fator principal para produzir mudanças de conteúdos curriculares: mencionou-se o como os alunos podem se manifestar contra o predomínio psicanalítico, ou mesmo apoiálo. Neste último caso, ressaltou-se que tem a ver com a "fascinação" produzida pela psicanálise, ligada ao mesmo tempo ao estilo de "transmissão" dos professores.

Por outro lado, a diversidade de opiniões em relação às divergências e disputas entre visões teóricas convergiu na metáfora de "times de futebol" nas duas cidades, apontando o dogmatismo e a falta de diálogo entre os representantes das distintas teorias. Neste sentido, afirmou-se que os agentes que promovem o discurso psicanalítico apresentam-no como se fosse superior aos outros discursos psicológicos. Esta ideia foi associada também ao status epistemológico particular das ideias freudianas.

Observou-se também que coexistem duas visões nos cursos de psicologia analisados. Por um lado, existe a perspectiva de promover uma psicologia generalista, ampla e multiteórica. Por outro lado, sublinha-se a ideia de que a psicanálise é fundamental para a psicologia, e que este olhar conta com uma forte tradição. Essas duas ideias se articulam e mostram que, nas disputas pela hegemonia curricular em psicologia nas duas cidades, a psicanálise pode encontrar-se associada a sentidos similares. Contrariamente à ideia da psicologização da psicanálise como um dos fatores da "crise" da disciplina freudiana, neste trabalho se observou que é nos cursos universitários de psicologia que o discurso psicanalítico encontra um espaço de desenvolvimento sólido dentro das culturas carioca e portenha. 
Os temas aqui abordados mostram que o fenômeno de expansão do discurso psicanalítico nas universidades cariocas e portenhas se encontra vinculado a aspectos históricos, institucionais e teóricos. Também se aponta que esta situação está relacionada tanto aos contextos nacionais quanto aos debates do movimento psicanalítico ao nível internacional.

Entende-se que esta pesquisa construiu uma comparação do fenômeno da expansão psicanalítica na universidade em duas cidades que, para além da crise atual da disciplina freudiana, resultam ser capitais mundiais da psicanálise e onde os cursos universitários de psicologia têm sido fortalecidos nas últimas décadas. Restaria conhecer como é que se produz esta situação em outras regiões desses dois países. Observe-se que é importante explorar este fenômeno em outras cidades além das grandes capitais, não somente para conhecer similaridades e diferenças com a situação aqui colocada, senão para compreender também a medida na qual o discurso psicanalítico vai associando-se a outras particularidades.

Finalmente, se espera que esta pesquisa contribua para os debates curriculares do Brasil e de Argentina, oferecendo parâmetros para os processos de revisão e avaliação dos cursos de Psicologia nos dois países. Essas avaliações devem considerar, por um lado, uma perspectiva histórica, que mostre questões - culturais, sociais e políticaspresentes na situação atual. Por outro lado, é preciso incluir também uma perspectiva que ultrapasse um olhar localista, $e$ analise os acontecimentos de outros países da região. Por meio deste artigo, se aspira ter colaborado com esses propósitos.

\section{Referências}

Alonso, M., \& Klinar, D. (2016, novembro). Los psicólogos en Argentina. Relevamiento cuantitativo 2015: Resultados Preliminares. Trabalho apresentado no VIII Congreso Internacional de Investigación y Práctica Profesional en Psicología, XXIII J ornada de Investigación e XII Encuentro de Investigadores de Psicología del Mercosur, Secretaría de Investigaciones, Facultad de Psicología, UBA, Argentina, 23-26.

Ardila, R. (1978). Conclusiones de la I Conferencia Latinoamericana sobre Entrenamiento en Psicología. In R. Ardila (Comp.), La Profesión del Psicólogo (pp. 220-227). México, D.F.: Trillas.

Bastos, A. V. B., \& Gondim, S. M. G. (Eds.). (2010). O Trabalho do psicólogo no Brasil. Porto Alegre: Artmed.

Birman, J. (2000). Entrevista com Joel Birman. Revista Latinoamericana de Psicopatología Fundamental, 4(2), 168-172.

Bourdieu, P. (2001). El oficio de científico. Ciencia de la ciencia y reflexividad. Barcelona: Anagrama. 
Bowman, P. (2007). Post-marxism versus cultural studies: theory, politics and intervention. Edinburgh: Edinburgh University Press.

Campuzano, M. (2005). La crisis actual del psicoanálisis. Revista da SPAGESP - Sociedade de Psicoterapias Analíticas Grupais do Estado de São Paulo, 6(1), 1-7.

Carpintero E., \& Vainer, A. (2005). Las huellas de la memoria. Psicoanálisis y Salud Mental en la Argentina de los ' 60 y' 70 (Tomos I y II). Buenos Aires: Topía.

Cerqueira, G. (Org.). (1982). Crise na psicanálise. Rio de Janeiro: Graal.

Coelho Junior, N. (1999). Psicanálise, Brasil e crise. Psicanálise Universidade, (9-10), 105-118.

Coimbra, C. (1999). Práticas "psi" no Brasil do "milagre": algumas de suas produções. In A. M. Jacó-Jacó-Vilela, F. Jabur, \& H. B. C. Rodrigues (Orgs.), Clio-Psyché: histórias da psicologia no Brasil (pp. 75-95). Rio de Janeiro: UERJ/NAPE.

Coutinho, D., Mattos, A. S., Monteiro, C. F. d'A., Virgens, P. A., \& Almeida Filho, N. M. (2013). Ensino da psicanálise na universidade brasileira: retorno à proposta freudiana. Arquivos Brasileiros de Psicologia, 65(1), 103-120.

Dagfal, A. (2009). Entre París y Buenos Aires. La invención del psicólogo (1945-1966). Buenos Aires: Paidós.

Dantas, F. H. A. (2017). A formação em Psicologia no contexto da democratização do ensino superior. (Dissertação de Mestrado). Universidade Federal do Rio Grande do Norte, Natal, RN.

Danziger, K. (1984). Towards a conceptual framework for a critical history of psychology. Revista de Historia de La Psicología, 5(1/2), 99-107.

Dias Sobrinho, J., \& Brito, M. R. F. (2008). La educación superior en Brasil: principales tendencias y desafíos. Avaliação: Revista da Avaliação da Educação Superior (Campinas), 13(2), 487-507.

Dimenstein, M. (2000). A cultura profissional do psicólogo e o ideário individualista: implicações para a prática no campo da assistência pública à saúde. Estudos de psicologia, 5(1), 95-121. doi:10.1590/S1413-294X2000000100006

Fernandes, S.R. F. (2016). Psicologia e formação generalista: do currículo mínimo às diretrizes curriculares. (Dissertação de Mestrado). Universidade Federal do Rio Grande do Norte, Natal, RN.

Figueira, S. A. (1985). Introdução: psicologismo, Psicanálise e Ciências Sociais na "cultura psicanalítica". In S. A. Figueira (Org.), Cultura da Psicanálise (pp.7-13). São Paulo: Brasiliense.

Figueiredo, A. C. (1984). Estratégias de Difusão do Movimento Psicanalítico no Rio de Janeiro (1970-1983). (Dissertação de Mestrado). Pontifícia Universidade Católica, Rio de Janeiro, RJ.

Figueiredo, A. C. (2012). A psicanálise dos psicólogos no Rio De Janeiro dos anos 1970. Culturas Psi, 1(1), 84-99. 
Gallegos, M. (2010). La primera Conferencia Latinoamericana sobre Entrenamiento en Psicología (1974): el modelo Latinoamericano y su significación histórica. Psicologia: Ciência e Profissão, 30(4), 792-809. doi:10.1590/S1414-98932010000400010

Garfield, E., Malin, M. V., \& Small, H. (1978). Citation data as science indicators. In Y. Elkana, J. Lederberg, R. K. Merton, A. Thackray, \& $\mathrm{H}$. Zuckerman (Eds.), Toward a metric of science: the advent of science indicators (pp. 580-608). New York: Wiley.

Garza-Guerrero, C. (2002). The crisis in psychoanalysis: what crisis are we talking about?. The International Journal of Psychoanalysis, 83(1), 57-83.

Hornstein, L. (2013). Las encrucijadas actuales del psicoanálisis: Subjetividad y vida cotidiana. Buenos Aires: Fondo de Cultura Económica.

Klappenbach, H. (2000). El psicoanálisis en los debates sobre el rol del psicólogo. Argentina, 1960-1975. Revista Universitaria de Psicoanálisis, 2, 191-227.

Lézé, S. (2010). L'autorité des psychanalystes. Paris: PUF.

Litvinoff, N., \& Gomel, S. (1975). El Psicólogo y su Profesión. Buenos Aires: Nueva Visión.

Lopes, A. C. (2013). Democracia nas políticas de currículo. Cadernos de Pesquisa, 42(147), 700-715. doi:10.1590/S010015742012000300003

Lopes, A. C., Evangelista Dias, R., \& Gomes de Abreu, R. (Org.). (2011). Discursos nas políticas do currículo. Rio de Janeiro: Quartet.

Macedo, E. (2006). Currículo como espaço-tempo de fronteira cultural. Revista Brasileira de Educação, 11(32), 285-296. doi:10.1590/S1413-24782006000200007

Pereira, W. C. C. (2007). Movimento institucionalista: principais abordagens. Estudos e Pesquisas em Psicologia, 7(1), 10-19.

Pereira, F. M., \& Pereira Neto, A. (2003). O psicólogo no Brasil: notas sobre seu processo de profissionalização. Psicologia em estudo, 8(2), 19-27. doi:10.1590/S1413-73722003000200003

Plotkin, M. (2003). Freud en las Pampas. Buenos Aires: Sudamericana.

Plotkin, M. (2009). Psicoanálisis y habitus nacional: un enfoque comparativo de la recepción del psicoanálisis en Argentina y Brasil (1910-1950). Memoria y Sociedad, 13(27), 61-86.

Porge, E., Chaumon, F., Lérès, G., Plon, M., Bruno, P., \& Aouillé, S. (2010). Manifesto pela psicanálise. Rio de Janeiro: Civilização Brasileira.

Roudinesco E., \& Plon, M. (1998). Diccionario de Psicoanálisis. Buenos Aires: Paidós.

Roudinesco, E. (2003). Estado del psicoanálisis en el mundo. In R. Major, (Dir.), Estados generales del psicoanálisis. Perspectivas para el tercer milenio (pp. 29-38). Buenos Aires. Siglo XXI. 
Roudinesco, E. (2012). Lacan, frente y contra todo. Buenos Aires: Fondo de Cultura Económica.

Russo, J. (1993). O corpo contra a palavra: as terapias corporais no campo psicológico dos anos 80 . Rio de Janeiro. Editora UFRJ.

Russo, J. (2002a). A difusão da psicanálise no Brasil na primeira metade do século XX. Da vanguarda modernista à radio-novela. Estudos e Pesquisas em Psicologia, 2(1), 51-61.

Russo, J. (2002b). O mundo psi no Brasil. Rio de Janeiro: Zahar.

Russo, J. (2012). Introdução ao Dossiê Brasil. Culturas Psi, 1(1), 22-25.

Seixas, P.S. (2014). A formação graduada em psicologia no Brasil: reflexão sobre os principais dilemas em um contexto pós-DCN (Tese de Doutorado). Universidade Federal do Rio Grande do Norte, Natal, RN.

Vezzetti, H. (1996a). Freud en Buenos Aires. Buenos Aires: Universidad Nacional de Quilmes.

Vezzetti, H. (1996b). Aventuras de Freud en el país de los argentinos: de J osé Ingenieros a Enrique Pichon-Rivière. Buenos Aires: Paidós.

Vezzetti, H. (2000). Historia del psicoanálisis: complejidad y producción historiográfica [conferencia]. In R. Ruiz, \& J. C. Stagnaro, P. Weissmann, Psiquiatría, psicología y psicoanálisis: historia y memoria (pp. 63-82). Buenos Aires: Polemos.

Werner, M., \& Zimmerman, B. (2006). Beyond Comparison: "Histoire Croisée" and the Challenge of Reflexivity. History and theory, 45, 30-50.

Yamamoto, O. H., Falcao, J. T. R., \& Seixas, P. S. (2011). Quem é o estudante de psicologia do Brasil?. Avaliação Psicológica (Impresso), 10, 209-232.

\section{Endereço para correspondência María Eugenia González}

Universidad Nacional de Salta - UNAS

Instituto de Investigaciones en Humanidades y Ciencias Sociales - ICSOH/CONICET Av. Bolivia, 5150, $2^{\circ}$ piso, Salta Capital, Salta, Argentina (A4408FVY)

Endereço eletrônico: eugeblur@gmail.com

Recebido em: $18 / 12 / 2018$

Reformulado em: 31/01/2019

Aceito em: 01/02/2019

\section{Notas}

* Pós-Doutoranda na Universidad Nacional de Salta (UNSA, Salta, Argentina), com financiamento do Consejo Nacional de Investigaciones Científicas y Técnicas (CONICET). Professora do Departamento de Psicologia da Universidad Católica de Salta (UCASAL, Salta, Argentina). Doutora em Psicologia pela Universidad Nacional de Córdoba (UNC, Córdoba. Argentina). Doutorado Sanduíche pela Universidade do Estado do Rio de Janeiro (UERJ, Rio de Janeiro, Brasil), com financiamento da Fundação de Amparo à Pesquisa do Rio de Janeiro (FAPERJ). Mestre em Psicanálise 
pela Universidad del Aconcagua (UDA, Mendoza, Argentina). Cientista Política pela Universidad Nacional de Cuyo (UNCuyo, Mendoza, Argentina).

${ }^{1}$ Além do protagonismo da área clínica nos cursos de Psicologia brasileiros, no que se refere ao aspecto teórico, Pablo de Sousa Seixas (2014) afirmou que a subjetividade constitui um dos tópicos mais ensinados nos cursos de Psicologia do Brasil, por meio de teorias psicodinâmicas. Estas contam com uma grande influencia da orientação psicanalítica.

${ }^{2}$ Ver: Por primera vez hay más alumnos inscriptos en Psicología que en Derecho de la UBA (2017, abril 4). Portal Infobae: Política. Recuperado de https://www.infobae.com/politica/2017/04/04/por-primera-vez-hay-mas-alumnosinscriptos-en-psicologia-que-en-derecho-de-la-uba/

${ }^{3} \mathrm{~A}$ análise institucional ou socioanálise é uma das modalidades do institucionalismo mais difundidas no Brasil a partir da década de 60. Surgiu como um prolongamento da Terapia Institucional, da Pedagogia Institucional, da Filosofia, da Sociologia Política e da Dinâmica de Grupo americana de Kurt Lewin e se direcionou em seguida para a análise de grupos sociais (Pereira, 2007). Esse olhar foi promovido no Rio de Janeiro principalmente por Gregorio Baremblitt, Chaim Samuel Katz, e Luiz Fernando Mello Campos, fundadores de IBRAPSI (Instituto Brasileiro de Psicanálise, Grupos e Instituições).

${ }^{4}$ Neste artigo, utilizou-se nomes fictícios para designar nossos entrevistados. Os nomes que começam com a letra "a" minúscula se referem aos professores argentinos, enquanto os com "a" maiúscula se referem a estudantes argentinos. Por outro lado, os nomes que começam com a letra " $b$ " minúscula se referem aos professores brasileiros, enquanto os com " $b$ " maiúsculas e referem aos estudantes brasileiros. Os nomes que começam com a letra " $C$ " maiúscula, se referem a coordenadores de cursos de graduação em psicologia. Neste último caso, como dito, somente foram consultados coordenadores de Rio de Janeiro, já que em Buenos Aires não todos os cursos escolhidos contam com essa função de coordenação.

5 Por análise bibliométrica aqui se entende à "quantificação da informação bibliográfica suscetível de ser analisada" (Garfield, Malin, Small,1978, p.180).

${ }^{6}$ No Rio de Janeiro não se trabalhou com os programas, mas com as ementas, que são mais curtas que os programas, porque no momento em que se procurou os programas das disciplinas escolhidas, muitas vezes os professores diziam que nem os tinham preparado, ou desmereciam esta documentação dizendo que em sala de aula decidiam na hora o que trabalhar com os alunos: "(Nos programas) A questão bibliográfica não vai estar bem." (bernardo).

7 O principal antecedente na América Latina da necessidade de uma formação geral e plural no aspecto teórico em Psicologia ocorreu durante a "Primera Conferencia Latinoamericana sobre Entrenamiento em Psicología" em Bogotá, Colombia, em 1974. O modelo científico- profissional previsto em Bogotá, segue o Modelo "Boulder", proposto em 1948 nos Estados Unidos (Ardila, 1978, Gallegos, 2010). A ideia de ensinar diversos campos de atuação, gerando um diplomaúnico de psicólogo, tem a ver com a proposta da formação generalista.

Financiamento: Fundação Carlos Chagas Filho de Amparo à Pesquisa do Estado do Rio de Janeiro (FAPERJ) - Consejo Nacional de Investigaciones Científicas y Técnicas (CONICET).

Este artigo de revista Estudos e Pesquisas em Psicologia é licenciado sob uma Licença Creative Commons Atribuição-Não Comercial 3.0 Não Adaptada. 